DOI: $10.12731 / 2306-1561-2013-4-8$

\title{
DEVELOPMENT MULTI-CHANNEL DIGITAL ELECTRICITY METERS, DESIGNED WITH THE AUTOMATED SYSTEM OF COMMERCIAL ACCOUNTING SYSTEM (ASCAS)
}

\author{
Shazhaev I.S., Mintsaev M.S., Magomedov I.A.
}

\section{Abstract}

The article describes a new kind of energy accounting device, with which it will be possible to develop technology on the organization of accounting and distribution of electricity in the city. The system is multi-channel digital electricity meter, which will significantly increase the level of customer service, reduce staff members supervising bodies, to reduce commercial losses and to more effectively distribute electrical energy. Also, this type of device energy accounting will reduce the cost of operating electric power supplier, as well as the costs of maintenance cost per customer by the relatively low cost of the multichannel count and ease of maintenance.

Keywords: counter, the consumer, accounting, energy, multi-channel, electric, payment, power consumption, system, network.

\section{УДК 681.3}

\section{РАЗРАБОТКА МНОГОКАНАЛЬНОГО ЦИФРОВОГО СЧЕТЧИКА ЭЛЕКТРИЧЕСКОЙ ЭНЕРГИИ, РАЗРАБОТАННОГО С УЧЕТОМ ТРЕБОВАНИЙ АВТОМАТИЗИРОВАННОЙ СИСТЕМЫ КОММЕРЧЕСКОГО УЧЕТА ЭЛЕКТРОЭНЕРГИИ (АСКУЭ)}

\section{Шажаев И. Ш., Минцаев М.Ш., Магомедов И.А.}

\section{Аннотация}

В статье описан новый вид прибора энергоучета, с помощьью которого можно будет разработать технологию по организации системы учета и распределения электрической энергии в условиях города. Основой системы является многоканальный ичифровой счетчик электрической энергии, который позволит существенно повысить уровень обслуживания потребителей, сократить итатных работников контролирующих органов, уменьшить коммерческие потери и более эффрективно распределять электрическую энергию. Также такой вид устройства энергоучета позволит сократить затрать энергопоставщика на эксплуатащию электросетей, $а$ также затраты на стоимость обслуживание одного потребителя за счет относительно низкой стоимости многоканального счетчика и простоты его обслужсивания. 
МАТЕРИАЛЫ ІХ МЕЖДУНАРОДНОЙ ЗАОЧНОЙ НАУЧНО-ПРАКТИЧЕСКОЙ КОНФЕРЕНЦИИ МОЛОДЫХ УЧЕНЫХ «ТЕОРИЯ И ПРАКТИКА ПРИМЕНЕНИЯ ИНФОРМАЦИОННЫХ ТЕХНОЛОГИЙ В ПРОМЫШЛЕННОСТИ И НА ТРАНСПОРТЕ», г. Москва, 12 ноября 2013 г.

Ключевые слова: счетчик, потребитель, учет, энергия, многоканальный, электрический, платеж, энергопотребление, система, сеть.

\section{Введение}

Торговля энергоресурсами в настоящее время основана на использовании автоматизированного приборного учета энергии, который сводит к минимуму участие человека при измерении, сборе и обработки данных. При наличии современной автоматизированной системы коммерческого учета электроэнергии (АСКУЭ) полностью контролируется весь процесс энергопотребления и имеется возможность по согласованию с поставщиками энергоресурсов гибко переходить к разным тарифным системам, минимизируя энергозатраты.

В статье предлагается системный подход к проектированию счетчиков электрической энергии (СЭЭ), который позволит наиболее эффективно организовать процесс автоматизированного учета и распределения электрической энергии в городских электрических сетях и уменьшит коммерческие потери электроэнергии [4].

\section{Современное состояние исследований по данному направлению}

Выпускаемые промышленностью многотарифные цифровые СЭЭ не ориентированы на создание единой автоматизированной системы по учету и распределению электрической энергии в городских условиях (г. Ставрополь, Москва и др) $[1$ - 3]. Известны СЭЭ которые имеют последовательный интерфейс для приемапередачи информации при наличии линий связи, что существенно усложняет систему и повышает стоимость СЭЭ. Кроме того, все известные СЭЭ не имеют средства автоматического отключения потребителя от сети при истечении оговоренного срока оплаты, что также приводит к необоснованному увеличению штатных работников контролирующих органов.

Многие фирмы в РФ также выпускают одноканальные цифровые многотарифные счетчики электроэнергии, в которых не предусмотрены аппаратные средства управления нагрузкой и средства по организации электронных платежей. Примерами таких счетчиков служат [1 - 4]:

- счетчики концерна «Энергомера», г. Ставрополь (более 50 наименований);

- счетчики компании «Инкотекс», (Меркурий, Сапфир»и др.), г. Москва;

- счетчики завода ОАО «СПЗ», г. Саранск и др.

Некоторыми фирмами выпускаются одноканальные счетчики аналогичные предлагаемому, например, фирма ООО «Телекарт-Прибор» выпускает счетчик (паспорт ААНЗ 466559200-13 ПС) электрической энергии многофункциональный типа «Энергия-9» (Украина, Одесса, ул. Жукова 105, oppu@telecard.com.ua) по цене 3500 руб. в которых предусмотрены аппаратные средства управления нагрузкой и средства по организации электронных платежей. 


\section{Описание многоканального счетчика электроэнергии}

Многоканальный счетчик заменяет 4 указанных счетчика типа «Энергия-9» и имеет расширенные функциональные возможности по сравнению с ним. Основным отличием многоканального счетчика от украинского является использования электронного платежного средства карточки iButton вместо обычных электронных карт, которые используются в счетчике «Энергия-9». Bce микросхемы iButton выполнены по жестким стандартам. Попробуйте согнуть их - это невозможно. Бросьте устройство на пол, наступите на него, опустите его в воду или в снег - корпус выдерживает механический удар $500 \mathrm{G}$, рабочий диапазон температур от $-40{ }^{\circ} \mathrm{C}$ до $+85^{\circ} \mathrm{C}$ не подвержен воздействию магнитных и статических полей, промышленной атмосферы. Обмен данным между счетчиком и электронной карточкой iButton происходит по протоколу 1-Wire.

Электронная карточка (ЭК) имеет оригинальный идентификационный номер, посредством которого к каждому счетчику электрической энергии (СЭЭ) ставится в соответствие ЭК, что позволит защитить информацию от несанкционированного доступа на всех этапах ее обработки. Кроме того, использование в качестве носителя информации ЭК позволяет организовать АСКУЭ практически в любом районе, где нет линий связи или нецелесообразно их использования, т.к. для построения АСКУЭ требуется обычная компьютерная сеть с простейшими устройствами считывания данных с ЭК и соответствующим программным обеспечением. Причем, поставщиком информации в этом случае является сам потребитель электроэнергии.

Система предполагает следующую схему взаимоотношений пользователя и энергоснабжающей организации. Заключается договор на обслуживание и установку счетчика. После установки счетчика электроэнергии, абонент проходит процедуру регистрации в системе и ему выдается идентификатор iButton типа DS1991/92, который имеет индивидуальный номер. Этот идентификатор с индивидуальным номером используется в качестве переносчика информации «АСКУЭ Счетчик» и для проведения дальнейших расчетов между потребителями и поставщиком электроэнергии, т.е. является электронной квитанцией.

Для внесения оплаты, потребитель производит съем информации со счетчика на ЭК и в ближайшем пункте производит оплату за использованный в кредит электроэнергию. При внесении пользователем оплаты с ЭК производится считывание всех данных и, в том числе, информации о попытках несанкционированного доступа (НСД). При наличии соответствующих условий электронная карточка iButton может быть использована и для организации платежей через Интернет без внесения, каких либо изменений в аппаратно-программные средства счетчика, а также по терминалам платежей сотовой связи.

\section{Функции многоканального счетчика в АСКУЭ}

Многоканальный счетчик электрической энергии будет являться основной составляющей автоматизированной системы коммерческого учета электроэнергии (АСКУЭ), и будет выполнять следующие функции: 
- учет и контроль электрической энергии в однофазных цепях переменного тока. Счётчик имеет испытательный (телеметрический) выход (основное передающее устройство), гальванически изолированный от остальных цепей счётчика, позволяющий производить поверку счётчиков, а также применять его в автоматизированных системах контроля и учёта электроэнергии (АСКУЭ).

- отключение и включение нагрузки посредством встроенного в счетчик электронного реле при наличии задолженности по платежам и/или при несанкционированном доступе к счетчику;

- организация многотарифного принципа учета электроэнергии без перепрограммирования счетчика (до 24 тарифов);

- организация двунаправленного обмена информацией «АСКУЭ $\square$ Счетчик» посредством идентификатора iButton типа DS1991/92, так как счетчик имеет встроенные средства считывания информации с идентификатора;

- защиты учетной информации и аппаратных средств счетчика от несанкционированного доступа ним (Счетчик имеет встроенные средства защиты от несанкционированного доступа). При снятии лицевой панели и/или панели колодки счетчик автоматически отключает потребителя от сети;

- защиты счетчика от перегрузки и оповещения потребителя о перегрузках.

Счетчик имеет четырехстрочный 10-ти символьный ЖК-дисплей, на котором отображается текущее значение потреблённой энергии и номер канала, содержащееся в энергонезависимом запоминающем устройстве, сохраняющем информацию при отключении счётчика. Информация до десятичной точки (5 старших разрядов) представляет значение потреблённой энергии непосредственно в киловатт-часах. Один младший разряд дисплея представляет десятые доли киловатт-часа, а один разряд номер канала.

\section{План разработки и изготовления многоканального счетчика электрической} энергии

Для проведения сравнительного анализа принципов построения многоканальных счетчиков электрической энергии разрабатываются альтернативные варианты структурных схем счетчика, а также алгоритмы функционирования счетчика. Критерием выбора основного варианта построения счетчика являются: точность учета, надежность и стоимость счетчика, а также функциональные возможности счетчика и удобства использования счетчика для построения беспроводных АСКУЭ.

На основе выбранного варианта разрабатываются принципиальные электрические схемы многоканального счетчика, техническую документацию на изготовления печатной платы, корпуса, лицевой панели и других составляющих счетчика, составляется ведомость покупных изделий и производится их заказ. Разрабатывается программное обеспечение для 4-х канального счетчика с использованием iButton технологий. 
По окончании изготовления печатной платы электронного блока счетчика производится его сборка и комплексная отладка аппаратных и программных средств счетчика. Производится проверка и испытания счетчика, по результатам испытания корректируются техническая документация и программное обеспечение. С целью проверки функциональных возможностей и работоспособности АСКУЭ, построенной на базе многоканального счетчика создается демоверсия расчетного центра.

\section{Заключение}

Разработка многоканального счетчика электрической энергии позволит создать эффективную, отвечающую современным требованиям АСКУЭ, которая позволит организовать процесс автоматизированного учета и распределения электрической энергии в городских электрических сетях и уменьшит коммерческие потери электроэнергии.

Сравнительный анализ, выпускаемых счетчиков показывает, что наиболее близким по функциональным возможностям многоканальному счетчиком является одноканальный многофункциональный счетчик электрической энергии фирмы ООО «Телекарт-Прибор» (паспорт ААНЗ 466559200-13 ПС) типа «Энергия-9» (Украина, Одесса, ул. Жукова 105, oppu@telecard.com.ua) по цене 3500 руб. в городе Москве.

Установка одного многоканального счетчика вместо 4-х одноканальных счетчиком типа «Энергия-9» с расширенными функциональными возможностями, позволит 2-2,5 раза сократить стоимость обслуживание одного потребителя за счет относительно низкой стоимости многоканального счетчика и простоты его обслуживания (рис. 1). Предлагаемый счетчик, стоимостью до 5000руб, заменяет 4 счетчика типа «Энергия-9» общей стоимостью 14000 руб.

\section{Список информационных источников}

[1] Магомедов И.А. Пашаев В.В., Принципы построения многоуровневых автоматизированных систем коммерческого учета электроэнергии в бытовом секторе. ДГТУ, 2009г.

[2] Минцаев. М.Ш. Пашаев В.В. Абдуллаев 3.Я. Аппаратное обеспечение и принципы построения автоматизированных систем коммерческого учета электроэнергии в бытовом секторе. МАДИ, 2012г.

[3] Официальный сайт фирмы «ООО Телекарт-Прибор» [Электронный ресурс] http://telecard.odessa.ua/ (Дата обращения 11.09.2013).

[4] Остроух, А.В. Информационные технологии в научной и производственной деятельности / [ред. А.В. Остроух] - М: ООО "Техполиграфцентр", 2011. - 240 с. ISBN 978-5-94385-056-1.

[5] Шажаев И.Ш., Минцаев М.Ш. Результаты реализации пилотного проекта по исследованию работы счетчиков электроэнергии «ЭНЕРГИЯ-9 // Автоматизация и управление в технических системах. - 2013. - № 2(4); URL: auts.esrae.ru/4-74 (дата обращения: 19.10.2013). 